\title{
Failure of nocturnal changes in growth hormone to alter carbohydrate tolerance the following morning
}

\author{
M.F. Nielsen, S. Dinneen, A. Basu, R. Basu, A. Alzaid, R. R. Rizza \\ Endocrine Research Unit, Mayo Clinic, Rochester, USA
}

\begin{abstract}
Summary To determine whether the increases in growth hormone that occur during sleep alter carbohydrate tolerance the following morning, two groups of volunteers were studied on two occasions. In one group saline alone was injected and infused (i.e. no octreotide) on one occasion and on the other octreotide was injected at 23.00 hours to inhibit endogenous growth hormone secretion followed by saline infusion to create a state of relative nocturnal growth hormone deficiency. In the other group the octreotide injection was followed on one occasion by a constant growth hormone infusion designed to maintain growth hormone concentrations at "basal" levels throughout the night whereas on the other it was followed by a constant infusion plus two supplemental growth hormone infusions given at midnight and
\end{abstract}

02.30 hours to mimic the normal nocturnal rise in growth hormone. The next morning, subjects were fed a radiolabelled mixed meal. The differences in the nocturnal growth hormone concentrations had no effect on the glucose, insulin, C-peptide and glucagon concentrations following breakfast ingestion nor did they alter postprandial rates of glucose production, disappearance or substrate oxidation. Thus, the normal nocturnal rise in growth hormone does not appear to be an important regulator of carbohydrate tolerance the following morning. [Diabetologia (1998) 41: 1064-1072]

Keywords Glucose production, glucose disappearance, splanchnic glucose uptake, gluconeogenesis.
In non-diabetic humans, glucose concentrations generally average $4-5.5 \mathrm{mmol} / \mathrm{l}$ following an overnight fast and rarely exceed 7-8 mmol/1 after eating [1-4]. This regulation of plasma glucose concentration occurs because glucose production is equal to glucose utilization in the fasting state and after eating endogenous glucose production rapidly falls while glucose uptake, by both hepatic and extrahepatic tissues, rapidly increases [1-4]. These responses are dependent on coordinated and appropriate interactions between insulin and counter insulin hormones. Growth hormone is a counter insulin hormone. An excess of growth hormone antagonizes insulin induced sup-

Received: 15 January 1998 and in revised form: 27 April 1998

Corresponding author: Dr. R. A. Rizza, Endocrine Research Unit, Mayo Clinic, 200 First Street S.W., Rochester, MN 55905, USA pression of endogenous glucose production and insulin induced stimulation of glucose uptake [5-11]. It also impairs glucose tolerance by increasing postprandial rates of glucose production, gluconeogenesis, and by decreasing postprandial rates of glucose uptake $[12,13]$. These anti-insulin effects are dose dependent and require several hours to develop after an increase in growth hormone concentration [5-11].

In contrast to the well established effects of an excess of growth hormone, little is known about the impact (if any) of the physiologic changes in plasma growth hormone concentration in daily living. Growth hormone concentrations vary considerably throughout the day in normal humans [12, 14-21]. Growth hormone concentrations fall when glucose concentrations rise and rise when glucose concentrations fall $[12,14]$. Increases are observed also in response to stress or exercise $[22,23]$ but perhaps the 
most consistent and pronounced increase occurs during the night [15-21]. Growth hormone generally increases to concentrations of about 5-15 $\mu \mathrm{g} / 11 \mathrm{~h}$ after the onset of sleep with a second peak occurring commonly 1-2 h later [15-21]. It is well established that a persistent increase of growth hormone to concentrations within this range impairs insulin action [6, 7]. It is not known whether the transient increases in growth hormone that occur typically during the night influence carbohydrate metabolism the following morning. Our studies were undertaken to answer this question.

\section{Subjects and methods}

Subjects. After approval by the Mayo Institutional Review Board, 16 healthy volunteers gave written informed consent to participate in the study. Volunteers were divided into two groups (Table 1), each group consisted of four men and four women matched for age and body mass index. None of the volunteers was on medication; all had normal fasting plasma glucose concentrations and none had a family history of diabetes mellitus. Subjects were studied on two occasions separated by at least one week with the exception of one subject in the second group who was unable to return for the saline alone study.

Experimental design. Volunteers were admitted to the Mayo General Clinical Research Center at 1700 hours on the evening before the study. At 1800 hours each ate a standard meal containing $800 \mathrm{kcal}$ (42\% carbohydrate, $38 \%$ fat and $20 \%$ protein). Thereafter, the subjects were permitted only water ad libitum until breakfast the following morning. On the evening of admission, an 18 gauge cannula was inserted into a forearm vein of each arm. One cannula was used for blood sampling and the other for hormone and tracer infusion. On one occasion, $0.1 \mathrm{ml}$ of $0.9 \%$ saline was injected subcutaneously at 2300 hours followed by a saline infusion to establish the nocturnal growth hormone profile that occurs in the absence of octreotide injection (referred to as the saline study). On the other occasion, $100 \mu \mathrm{g}$ of octreotide was injected subcutaneously at 2300 hours to inhibit endogenous growth hormone secretion [24]. This was followed by a saline infusion to create a state of relative growth hormone deficiency during the night (referred to as the deficient growth hormone study). The second group of subjects was studied also on two occasions. At 2330 hours, $100 \mu \mathrm{g}$ of octreotide was injected subcutaneously after which an intravenous infusion of growth hormone was started at a rate of $1 \mathrm{ng} \cdot \mathrm{kg}^{-1} \cdot \mathrm{min}^{-1}$ to maintain growth hormone concentrations constant at "basal" levels throughout the night (referred to as the basal growth hormone study). On a second occasion, this "basal" growth hormone infusion was supplemented by two additional growth hormone infusions at a dose of $17 \mathrm{ng} \cdot \mathrm{kg}^{-1} \cdot \mathrm{min}^{-1}$ given for $1 \mathrm{~h}$ beginning at midnight and 0230 hours to mimic the normal rise in growth hormone that typically occurs during the night (referred to as the variable growth hormone study). The "basal" growth hormone infusion was discontinued at 1130 hours the following day. The order of study was random. Neither insulin nor glucagon were replaced on any of the octreotide study days.

At 0500 hours, infusions of $\left[6-{ }^{3} \mathrm{H}\right]$ glucose $(16 \mu \mathrm{Ci}$ prime, $0.16 \mu \mathrm{Ci} / \mathrm{min}$ continuous) and $\mathrm{NaH}^{14} \mathrm{CO}_{3}(110 \mu \mathrm{Ci}$ prime, $1.10 \mu \mathrm{Ci} / \mathrm{min}$ continuous) were started to measure glucose
Table 1. Subject characteristics

\begin{tabular}{llllll}
\hline & Sex & $\begin{array}{l}\text { Age } \\
(\text { years })\end{array}$ & $\begin{array}{l}\text { Height } \\
(\mathrm{cm})\end{array}$ & $\begin{array}{l}\text { Weight } \\
(\mathrm{kg})\end{array}$ & $\begin{array}{l}\text { BMI } \\
\left(\mathrm{kg} / \mathrm{m}^{2}\right)\end{array}$ \\
\hline Group 1 & $\begin{array}{l}4 \text { men / } \\
4 \text { women }\end{array}$ & $24 \pm 5$ & $173 \pm 13$ & $76 \pm 18$ & $25 \pm 4$ \\
Group 2 & $\begin{array}{l}4 \text { men / } \\
4 \text { women }\end{array}$ & $25 \pm 4$ & $173 \pm 10$ & $75 \pm 15$ & $24 \pm 2$ \\
\end{tabular}

turnover and the rate of incorporation of ${ }^{14} \mathrm{CO}_{2}$ into glucose (a qualitative index of gluconeogenesis). The overnight sampling cannula was removed at 0700 hours and an 18-gauge cannula was inserted retrogradely in a contralateral hand vein. The hand was placed in a Plexiglas box and heated to $55^{\circ} \mathrm{C}$ to permit sampling of arterialized venous blood. A mixed meal containing $50 \mathrm{~g}$ dextrose and $100 \mu \mathrm{Ci}\left[2-{ }^{3} \mathrm{H}\right]$ glucose was eaten at 0800 hours. Each volunteer drank $100 \mathrm{ml}$ water containing $10 \mathrm{~g}$ D-xylose with breakfast to enable carbohydrate absorption to be estimated [25].

Blood and breath were sampled at 2-h intervals throughout the night and at 10-15 min intervals immediately before and for the first $2 \mathrm{~h}$ after eating breakfast, then at hourly intervals thereafter. Blood samples were placed on ice, centrifuged at $4{ }^{\circ} \mathrm{C}$, and stored at $20^{\circ} \mathrm{C}$ until assay. Breath was collected throughout the study for measurement of ${ }^{14} \mathrm{CO}_{2}$ specific activity [26] as well as the rates of oxygen consumption and carbon dioxide production for calculation of rates of substrate oxidation [27].

Analysis techniques. Plasma glucose and lactate concentrations were measured using glucose and lactate oxidase methods (Yellow Spring Instruments, Inc., Yellow Springs, Ohio, USA). Plasma insulin, C-peptide, and glucagon concentrations were measured by radioimmunoassay using reagents from Linco (Linco Research, Inc. St. Louis, Mo., USA). Plasma growth hormone and cortisol concentrations were measured using reagents from ICN Biomedicals (Costa Mesa, Calif., USA) and Ciba Corning (Norwood, Mass., USA). Plasma non-esterified fatty acid concentrations were measured using a kit from Wako (Wako Pure Chemical Industries, Ltd, Osaka, Japan). Plasma D-xylose concentrations were measured using a colorimetric method [25]. Determination of $\left[6-{ }^{3} \mathrm{H}\right]$ glucose and [2$\left.{ }^{3} \mathrm{H}\right]$ glucose specific activities was by selective enzymatic detritiation as described previously [28].

Calculations. Rates of glucose appearance and disappearance were calculated using Steele's non-steady state equations [29] in which the pool correction factor was assumed to equal 0.65 and the volume of distribution of glucose to equal $200 \mathrm{ml} / \mathrm{kg}$. The systemic rate of appearance of the ingested glucose was determined by tracing the rate of appearance of $\left[2-{ }^{3} \mathrm{H}\right]$ glucose contained in the meal with $\left[6-{ }^{3} \mathrm{H}\right]$ glucose as described previously $[25,30]$. Endogenous glucose production was calculated by subtracting the rate of appearance of the ingested glucose from the total systemic rate of appearance $[4,30]$. The per cent of glucose derived from ${ }^{14} \mathrm{CO}_{2}$ was calculated by dividing the specific activity of $\left[6-{ }^{14} \mathrm{C}\right]$ glucose by the specific activity of ${ }^{14} \mathrm{CO}_{2}$ and multiplying by 100 [30]. Since the specific activity of phosphoenolpyruvate is not known, this calculation provides a qualitative rather than a quantitative estimate of gluconeogenesis [30-32]. The advantages and limitations of this method of estimating gluconeogenesis have been discussed previously in detail [30-32]. Rates of glucose turnover could not be calculated in one subject due to inadvertent interruption of the tracer infusion during one of "basal" growth hor- 
mone study days. Carbohydrate and lipid oxidation were calculated using the equations of Frayn [33].

Statistical analysis. Data in text and figures are expressed as mean \pm SEM. To avoid the problems associated with multiple comparisons, composite parameters were calculated for each subject and used for statistical comparisons. Mean concentrations from 0100 hours to 0500 hours were compared to test for differences in nocturnal glucose and hormone concentrations. Mean concentrations and rates of turnover observed from 30 to 0 min were used to test for preprandial differences and total areas above zero (calculated using the trapezoidal rule) were used to test for postprandial differences. Analysis of variance was used to test for overall differences on the four study days. Student's paired $t$-test was then used to test for differences within a group (e.g. to compare results obtained during the variable growth hormone studies with those obtained during the basal growth hormone studies) whereas Student's nonpaired $t$-test was used to test for differences between groups (e.g. to compare results obtained during basal growth hormone studies with those obtained during the deficient growth hormone studies). A one tailed test was used to test the hypothesis that nocturnal growth hormone concentrations were lower during the octreotide study than those observed during the constant "basal" growth hormone study. All other tests were two tailed. A $p$ value less than 0.05 was considered statistically significant.

\section{Results}

Nocturnal growth hormone, glucose, insulin, C-peptide, glucagon and cortisol concentrations. Growth hormone concentrations rose during the two supplemental growth hormone infusions to peaks of about $9 \mu \mathrm{g} / \mathrm{l}$ at 0030 and 0300 hours, respectively (Fig. 1, upper panel). They remained at this level for $1 \mathrm{~h}$ then returned promptly to basal values following discontinuation of the supplemental growth hormone infusion. The timing and pattern of the first increase in growth hormone was similar to (albeit somewhat lower) that during the saline experiments when octreotide was not given. The second peak at 0330 hours exceeded growth hormone concentrations over the same interval during the saline experiments. In contrast, growth hormone concentrations remained constant throughout the night during the "basal" study averaging $3.1 \pm 0.3 \mu \mathrm{g} / \mathrm{l}$ which were slightly but significantly greater $(p<0.05)$ than those observed when growth hormone was not replaced $(2.4 \pm 0.2 \mu \mathrm{g} / \mathrm{l})$ thus creating a state of relative growth hormone deficiency.

After injection of octreotide, nocturnal glucose concentrations increased by equal amounts on the three study days reaching a peak of about $6.2 \mathrm{mmol} / \mathrm{l}$ at 0300 hours and falling back to basal levels of about $5.4 \mathrm{mmol} / 1$ by 0800 hours (Fig. 1, second panel) and remained higher $(p<0.05)$ than those observed at the same time during the saline experiments $(4.8 \pm$ $0.13 \mathrm{mmol} / \mathrm{l})$. Similarly, injection of octreotide resulted in a comparable and equal fall $(p<0.05)$ in insulin
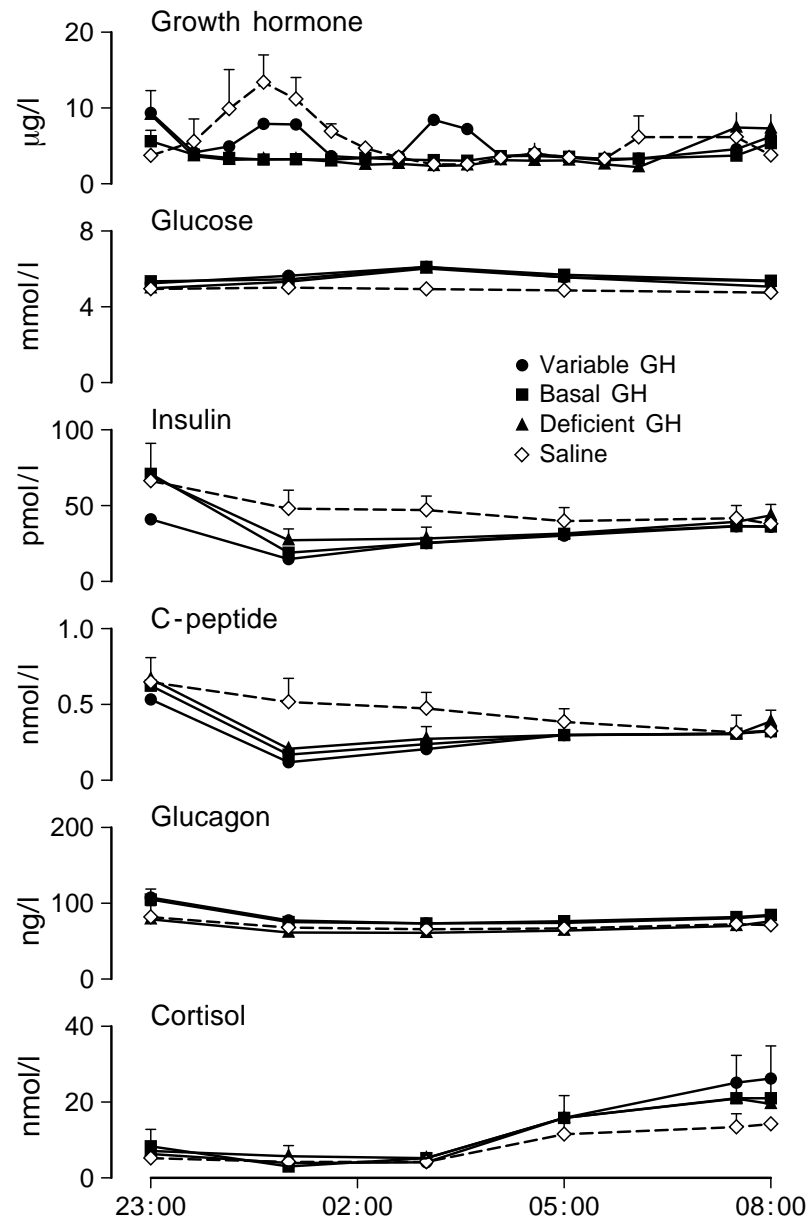

Fig. 1. Nocturnal growth hormone, glucose, insulin, C-peptide, glucagon and cortisol concentrations. Either saline (saline study) or octreotide were injected subcutaneously at 2300 hours. When octreotide was injected, growth hormone concentrations were either increased by two supplemental 1-h growth hormone infusions initiated at midnight and 0230 hours (variable GH), kept constant at basal levels by means of a continuous growth hormone infusion (basal $\mathrm{GH}$ ), or permitted to fall (deficient GH)

(Fig. 1, third panel) and C-peptide concentrations (Fig. 1, fourth panel) to a nadir at 0100 hours followed by a rise back to values at 0800 hours which no longer differed from those during the overnight saline infusion. Nocturnal glucagon and cortisol concentrations were not significantly different on the four study days (Fig. 1, lower panels).

Postprandial glucose, insulin, C-peptide, glucagon and growth hormone concentrations. Glucose concentrations increased by an almost identical amount on all four study days reaching a peak of about $9 \mathrm{mmol} /$ 1 at $60 \mathrm{~min}$ and returning to basal values by $3 \mathrm{~h}$ (Fig. 2). Postprandial insulin and C-peptide concentrations did not differ on the variable, basal or growth hormone deficient study days. The integrated insulin response above basal after eating a meal on those three occasions tended ( $p=0.04$ to 0.07$)$ to be lower, 


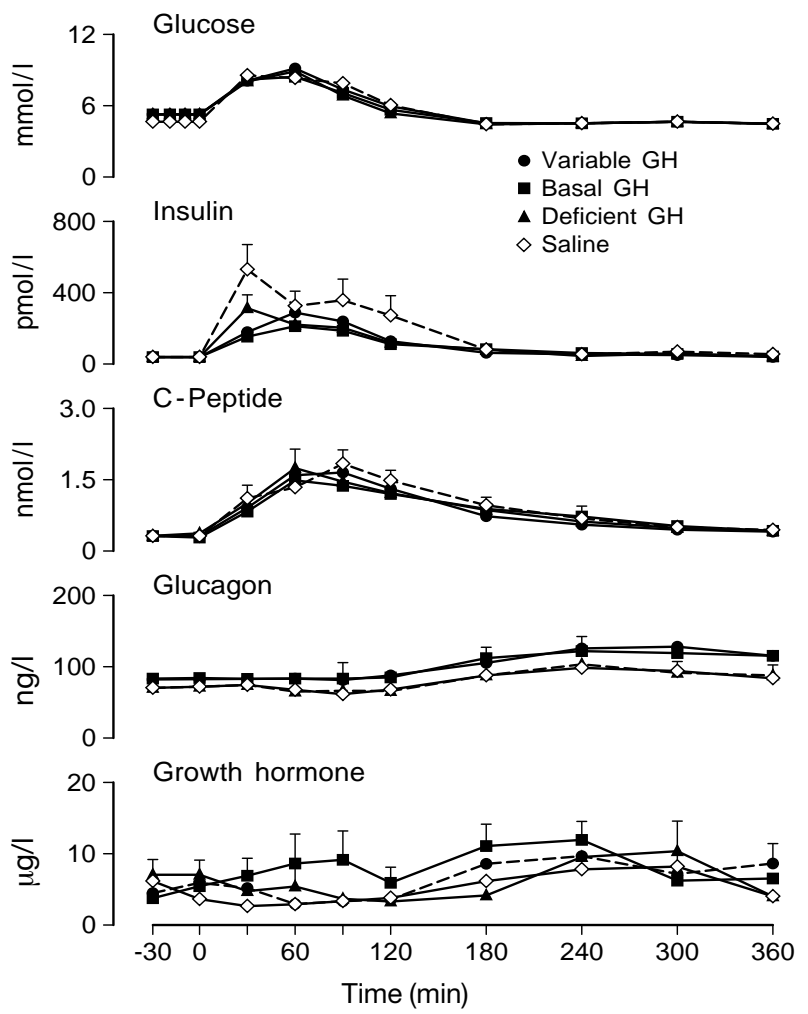

Fig. 2. Glucose, insulin, C-peptide, glucagon and growth hormone concentrations observed before and after breakfast eaten at time zero. Either saline (saline study) or octreotide were injected subcutaneously at 2300 hours. When octreotide was injected, growth hormone concentrations were either increased by two supplemental 1-h growth hormone infusions initiated at midnight and 0230 hours (variable $\mathrm{GH}$ ), kept constant at basal levels by means of a continuous growth hormone infusion (basal $\mathrm{GH}$ ), or permitted to fall (deficient $\mathrm{GH})$

however, than that after overnight saline infusion, implying that the octreotide injected the evening before continued on the following morning to blunt insulin secretion or increase insulin action. In contrast, postprandial glucagon (Fig.2, lower panel) and cortisol (data not shown) were not significantly different on any occasion.

Postprandial growth hormone concentrations showed considerable variability. Growth hormone concentration consistently increased in all subjects 2-3 $\mathrm{h}$ after eating a meal coincident with the fall in glucose concentrations toward basal levels. This rise, however, was superimposed on antecedent pulses in growth hormone secretion which began prior to eating a meal in six of the subjects. These preprandial pulses, which presumably were due to the waning of the effects of the octreotide, occurred in two subjects in the variable group, in three subjects in the "basal" group and in three subjects in the "deficient" group. Preprandial increases in growth hormone were also observed in two subjects in the saline group.
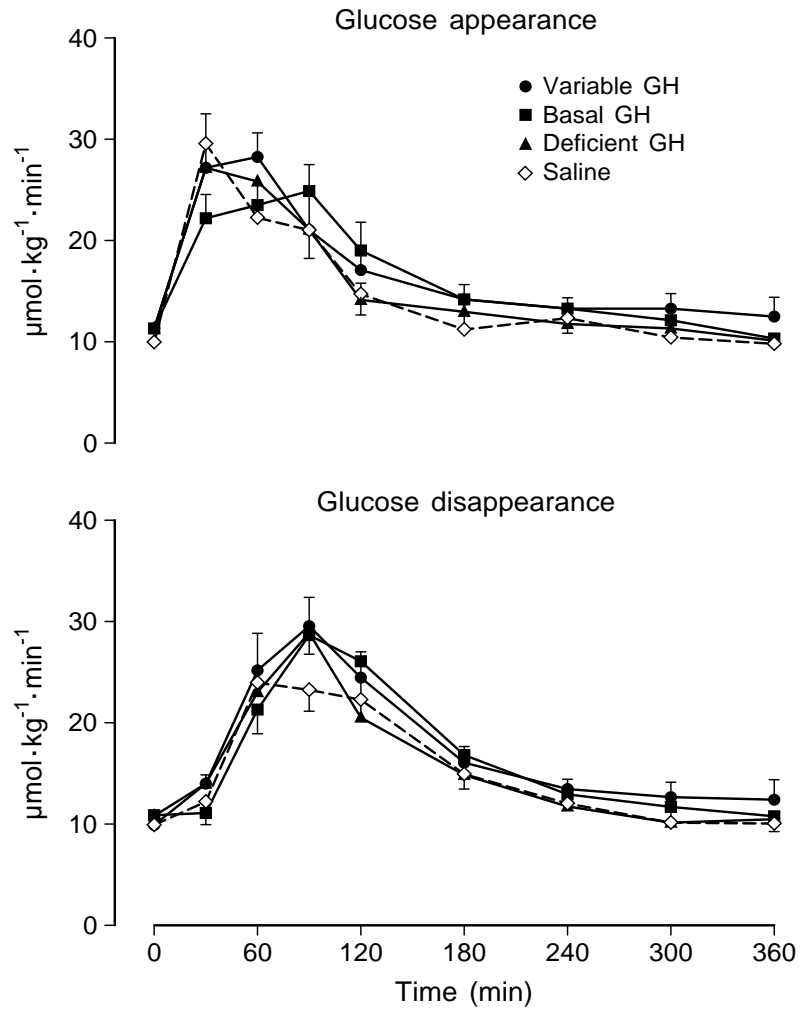

Fig. 3. Rates of glucose appearance and disappearance before and after breakfast eaten at time zero. Either saline (saline study) or octreotide were injected subcutaneously at 2300 hours. When octreotide was injected, growth hormone concentrations were either increased by two supplemental 1-h growth hormone infusions initiated at midnight and 0230 hours (variable $\mathrm{GH}$ ), kept constant at basal levels by means of a continuous growth hormone infusion (basal GH), or permitted to fall (deficient GH)

Rates of glucose disappearance, appearance and incorporation of ${ }^{14} \mathrm{CO}_{2}$ into glucose. Despite differences in nocturnal growth hormone concentrations, rates of appearance and disappearance did not differ on any of the four occasions either prior to or following eating (Fig. 3). In addition, both the degree of postprandial suppression of endogenous glucose production and the rate of incorporation of ${ }^{14} \mathrm{CO}_{2}$ into glucose were also the same on all four occasions (Fig.4).

Appearance of ingested glucose and plasma D-xylose concentrations. Postprandial glucose appearance equals the sum of the rate of appearance of the ingested glucose and endogenous glucose production. Appearance of the ingested glucose (Fig.5) was almost identical when endogenous secretion was inhibited by octreotide and when nocturnal growth hormone concentrations increased by a variable growth hormone infusion $(2.8 \pm 0.2)$, held at basal levels by a constant growth hormone infusion (2.6 \pm $0.2 \mathrm{mmol} \cdot \mathrm{kg}^{-1} \cdot 6 \mathrm{~h}^{-1}$ ) or was permitted to change unencumbered during the overnight saline infusion 

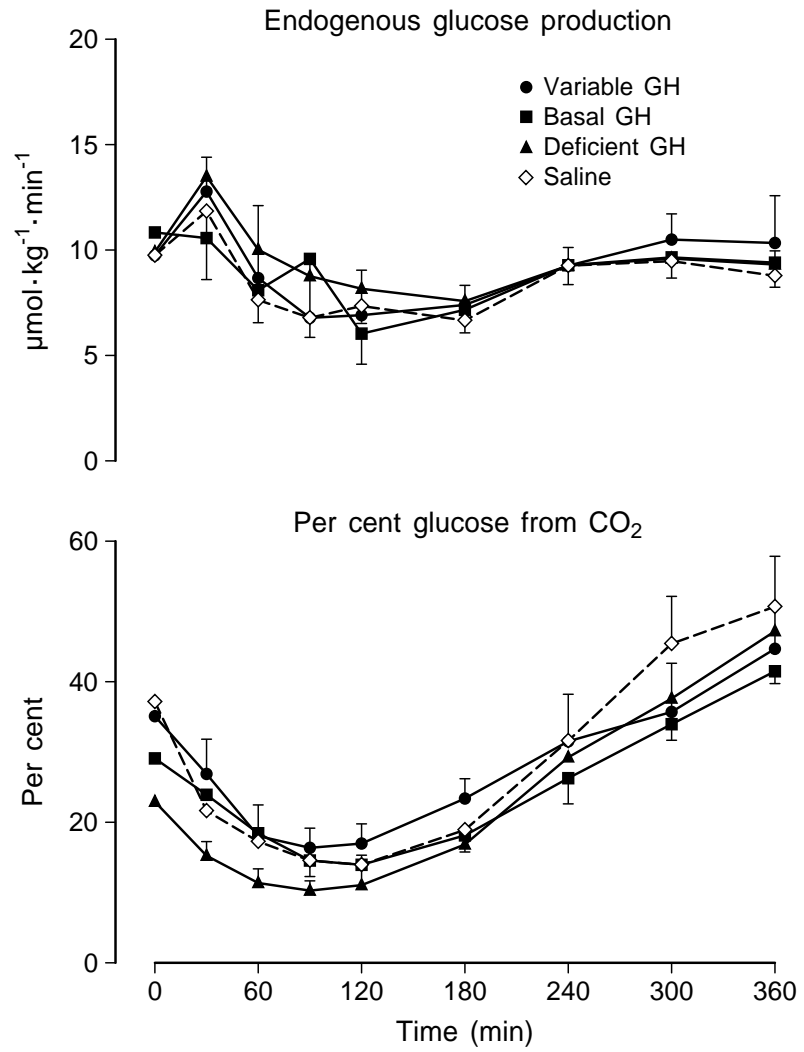

Fig. 4. Rates of endogenous glucose production and the per cent incorporation of ${ }^{14} \mathrm{CO}_{2}$ incorporation into glucose before and after breakfast eaten at time zero. Either saline (saline study) or octreotide were injected subcutaneously at 2300 hours. When octreotide was injected, growth hormone concentrations were either increased by two supplemental 1-h growth hormone infusions initiated at midnight and 0230 hours (variable GH), kept constant at basal levels by means of a continuous growth hormone infusion (basal $\mathrm{GH}$ ), or permitted to fall (deficient $\mathrm{GH}$ )

$\left(2.3 \pm 0.1 \mathrm{mmol} \cdot \mathrm{kg}^{-1} \cdot 6 \mathrm{~h}^{-1}\right)$. Appearance of ingested glucose after overnight growth hormone deficiency $\left(2.1 \pm 0.2 \mathrm{mmol} \cdot \mathrm{kg}^{-1} \cdot 6 \mathrm{~h}^{-1}\right)$ was, however, slightly lower ( $p=0.02,0.04,0.05$, respectively) than that on the other three occasions.

Postprandial plasma D-xylose concentrations did not differ on the four study days indicating that octreotide injection the previous evening did not alter gut absorption the following morning.

Plasma lactate and non-esterified fatty acid concentrations and rates of carbohydrate and lipid oxidation. Plasma lactate concentrations did not differ either prior to or after eating on the variable, basal and deficient study days (Fig. 6, upper panel). Although preprandial lactate concentrations on the saline study day tended to be slightly lower than on the three octreotide study days, the postprandial increase above basal did not differ on any of the four occasions.

Preprandial plasma non-esterified fatty acid concentrations were lower after overnight growth hor-
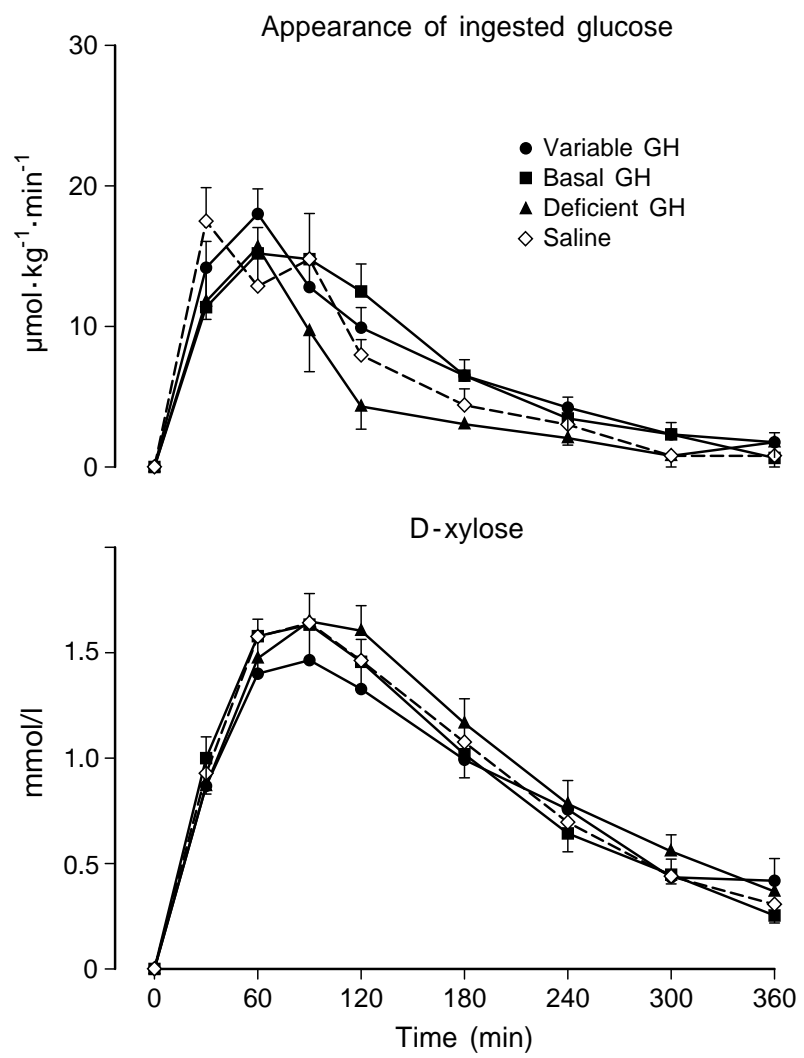

Fig.5. Rates of appearance of ingested glucose and plasma DXylose concentrations before and after breakfast eaten at time zero. Either saline (saline study) or octreotide were injected subcutaneously at 2300 hours. When octreotide was injected, growth hormone concentrations were either increased by two supplemental 1-h growth hormone infusions initiated at midnight and 0230 hours (variable GH), kept constant at basal levels by means of a continuous growth hormone infusion (basal $\mathrm{GH}$ ), or permitted to fall (deficient $\mathrm{GH}$ )

mone deficiency $(0.27 \pm 0.05 \mathrm{mmol} / \mathrm{l})$ than after either overnight saline $(0.57 \pm 0.09 \mathrm{mmol} / \mathrm{l} ; p=0.02)$, basal $(0.55 \pm 0.06 \mathrm{mmol} / \mathrm{l} ; \quad p=0.01)$ or variable $(0.51 \pm 0.05 \mathrm{mmol} / \mathrm{l} ; p=0.005)$ growth hormone infusions (Fig. 6, lower panel). Eating resulted in prompt and almost identical suppression of non-esterified fatty acids on all four occasions. In addition, postprandial rates of carbohydrate and lipid oxidation were similar on all study days (Fig. 7).

\section{Discussion}

Maintenance of normal carbohydrate tolerance requires the interaction of insulin and the counter insulin hormones [1-4]. Cortisol and growth hormone are well established as counter insulin hormones [5-13, $34,35]$. Numerous studies have established that excessive amounts of cortisol or growth hormone cause carbohydrate intolerance and insulin resistance [5-13, 34, 35]. Both impair insulin induced suppres- 

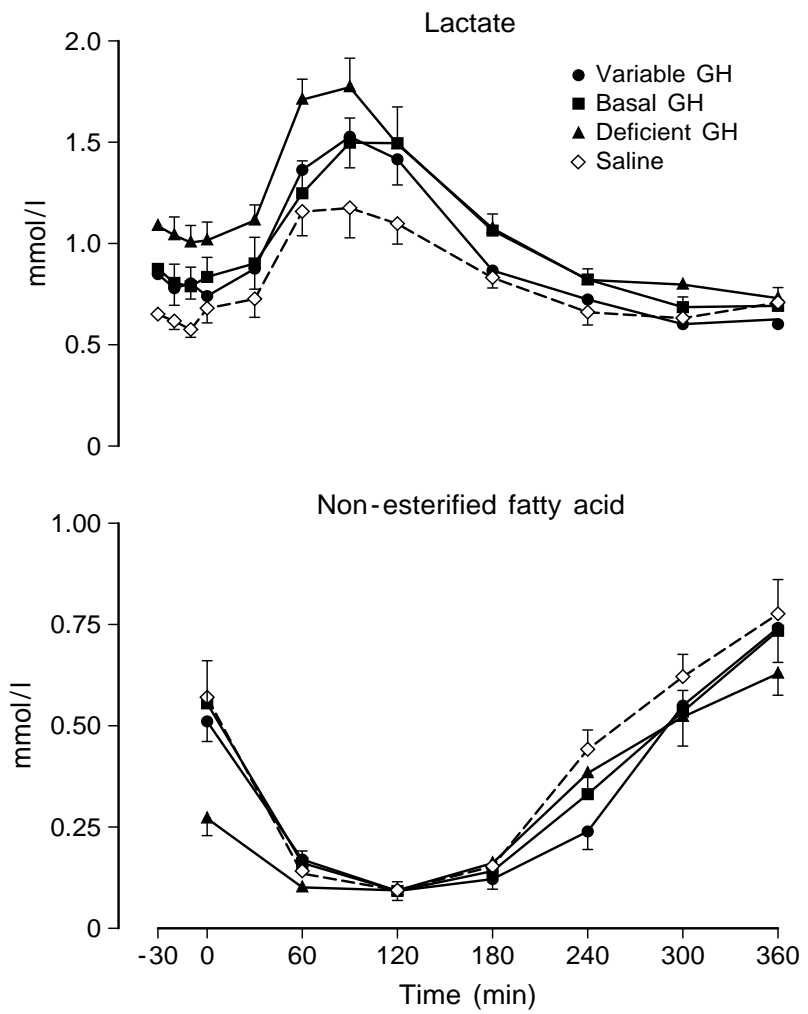

Fig. 6. Plasma lactate and non-esterified fatty acids concentrations before and after breakfast eaten at time zero. Either saline (saline study) or octreotide were injected subcutaneously at 2300 hours. When octreotide was injected, growth hormone concentrations were either increased by two supplemental 1-h growth hormone infusions initiated at midnight and 0230 hours (variable GH), kept constant at basal levels by means of a continuous growth hormone infusion (basal $\mathrm{GH}$ ), or permitted to fall (deficient $\mathrm{GH})$

sion of hepatic glucose release and insulin induced stimulation of glucose uptake $[34,35]$. In the absence of an appropriate compensatory increase in insulin secretion, both cause hyperglycaemia $[12,13,25,36]$. The effects of physiologic changes in these hormones on carbohydrate metabolism have received less attention. We and others have shown that the normal nocturnal rise in cortisol is an important regulator of carbohydrate tolerance the following morning [25, $36,37]$. The present experiments suggest that this may not be the case for growth hormone. Glucose concentrations after eating breakfast were virtually identical whether growth hormone concentrations the preceding night were episodically increased, maintained constant at basal levels or reduced to deficient levels. Moreover, postprandial stimulation of glucose uptake and oxidation and suppression of glucose production and lipid oxidation were also the same on all occasions.

Growth hormone has both acute insulin-like [38-40] and anti-insulin effects [5-13]. The insulinlike effects are rapid, minimal and evanescent [38-40]. The anti-insulin effects are delayed and are
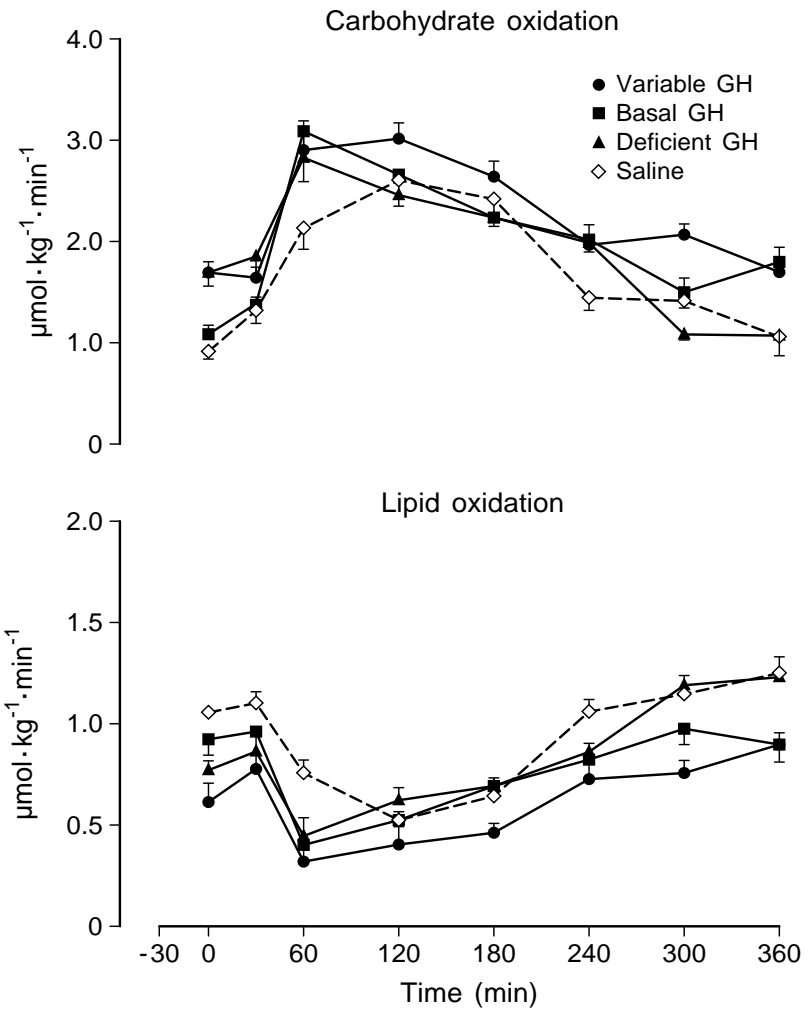

Fig. 7. Carbohydrate and lipid oxidation before and after breakfast eaten at time zero. Either saline (saline study) or octreotide were injected subcutaneously at 2300 hours. When octreotide was injected, growth hormone concentrations were either increased by two supplemental 1 -h growth hormone infusions initiated at midnight and 0230 hours (variable $\mathrm{GH}$ ), kept constant at basal levels by means of a continuous growth hormone infusion (basal GH), or permitted to fall (deficient $\mathrm{GH})$

dependent on both the dose and manner in which growth hormone is given [5-13, 41, 42]. Maintenance of growth hormone concentrations at about $9 \mu \mathrm{g} / \mathrm{l}$ for several hours produces insulin resistance [6-8]. In the present experiment, although growth hormone peaked at about $9 \mu \mathrm{g} / \mathrm{l}$ at 0030 and 0330 hours, these peaks were brief with growth hormone concentrations returning to basal levels within $1 \mathrm{~h}$. The timing and pattern of the first increase in growth hormone mimicked closely (albeit concentrations were somewhat lower) that during the saline experiments when octreotide was not given. The second peak at 0330 hours exceeded growth hormone concentrations over the same interval during the saline experiments. Breakfast was eaten at 0800 hours approximately $4 \frac{1}{2}$ $\mathrm{h}$ after the second growth hormone peak. Despite this, postprandial glucose, insulin and C-peptide concentrations did not differ from those during the basal infusion. Comparison of results during the variable and basal growth hormone infusions obviates uncertainty introduced by any residual effects of octreotide the following morning since it was injected the evening before on both occasions in identical amounts. 
This conclusion is further strengthened by the fact that the results on the three octreotide study days were virtually identical to those on the saline study day. Several studies have shown that although an acute increase in growth hormone can impair glucose uptake, its anti-insulin effects are transient and no longer evident $5 \mathrm{~h}$ later [42, 43]. A similar circumstance appears to occur after a nocturnal rise in growth hormone in that a metabolic effect is no longer detectable the following morning.

Based on previous reports [15-20], we elected to produce two nocturnal peaks of equal size. Growth hormone secretion is, however, extremely variable [15-20]. Peak concentrations during the variable growth hormone experiments averaged about $9 \mu \mathrm{g} / \mathrm{l}$ whereas those on the saline experiments averaged about $14 \mu \mathrm{g} / \mathrm{l}$. On the other hand, the variable infusion resulted in a second peak that clearly exceeded that during the saline study. This if anything should have enhanced our ability to detect an effect of growth hormone. Higher plasma growth hormone concentrations than those produced in the present experiment can occur in young people particularly around the time of puberty [44] and lower concentrations with obesity or ageing [20, 45, 46]. Thus, we cannot rule out the possibility that higher and more frequent nocturnal increases in growth hormone than those produced in the present experiments may exert metabolic effects the following morning in some people.

Relative growth hormone deficiency was produced by injecting octreotide without an accompanying replacement with a growth hormone infusion. Nocturnal growth hormone concentrations in these experiments were only slightly (but significantly) lower than those during the basal growth hormone experiments. It is likely that the small differences in growth hormone concentrations, at least in part, are because they were measured with a first generation growth hormone assay the detection limit of which was about $2 \mu \mathrm{g} / \mathrm{l}$. Furthermore, we used a relatively small dose of octreotide. Even this subtle degree of growth hormone deficiency appeared to be sufficient to lower postabsorptive non-esterified fatty acid concentrations. It is therefore possible there would have been more pronounced effects had we created a greater degree of deficiency by giving higher doses of octreotide for a longer period.

Although the pattern of postprandial hepatic glucose metabolism was the same in the presence and absence of a nocturnal increase in growth hormone, it differed after nocturnal growth hormone deficiency in that meal glucose appearance and plasma non-esterified fatty acids were lower than on the other three study days. Since multiple statistical tests were performed, it is possible that both of these observations occurred by chance alone. We doubt that this was the case, since in both instances the results on the growth hormone deficient day were significantly lower than those on all of the other three study days. A decrease in meal glucose appearance could result from an increase in hepatic glycogen synthesis or an increase in splanchnic (or liver) glycolysis or both. No previous studies have examined the effects of acute relative growth hormone deficiency on either of these processes. In contrast, growth hormone is known to be a potent lipolytic hormone [47]. After giving growth hormone, plasma non-esterified fatty acid concentrations generally increase more and earlier than glucose concentrations $[9,41,42]$. Since plasma non-esterified fatty acid concentration and turnover are closely linked [48, 49], the lower concentrations after overnight growth hormone deficiency implies lower rates of lipolysis. This observation suggests that small "permissive" amounts of growth hormone are required for normal rates of lipolysis.

As with all experiments, the present studies have limitations. Octreotide was injected subcutaneously at 2300 hours on the evening prior to study to inhibit endogenous growth hormone secretion thereby enabling us to produce different growth hormone profiles during the night. Octreotide inhibits the secretion of hormones other than growth hormone. As is evident from Figs. 1 and 2, octreotide inhibited insulin (and perhaps glucagon) secretion during the night and blunted insulin secretion or increased insulin action or both after breakfast relative to that on the saline study day. Although this complicated comparison of the results of the saline experiments with the octreotide experiments, it did not hinder comparison of the three octreotide experiments since insulin, Cpeptide and glucagon concentrations were virtually identical during the night and after eating on all three occasions. Furthermore, the slightly lower postprandial insulin concentrations during the octreotide experiments relative to the saline experiments, if anything, presumably would accentuate any residual anti-insulin effect of the nocturnal increases in growth hormone. No such effect was observed.

In summary, glucose, insulin, C-peptide and glucagon concentrations were virtually identical whether or not breakfast was preceded by a nocturnal rise in growth hormone. Moreover, glucose appearance, disappearance, endogenous glucose production and $\mathrm{CO}_{2}$ incorporation into glucose did not differ in the presence or absence of the nocturnal rise in growth hormone concentration. Taken together with previous studies, these data indicate that although growth hormone excess can cause insulin resistance [5-10], transient increases in growth hormone during the night do not appear to cause a detectable alteration in postprandial carbohydrate metabolism the following morning. On the other hand, due to variability potentially introduced by concordant changes in insulin, glucagon and growth hormone concentrations during the night, the present experiments cannot totally rule 
out a small but undetected glucoregulatory effect of growth hormone on carbohydrate metabolism.

Acknowledgements. We thank C. Etter, T. Madson, D. Nash for their technical assistance; A. Wagner for assistance in preparation of the manuscript; and the staff of the Clinical Research Center for assistance in performing the studies. This work was supported by U.S. Public Health Service (DK29953, RR00585), and the Mayo Foundation. Dr. A. Basu was supported by a mentor-based American Diabetes Association Research Fellowship Award. Dr. S Dinneen received funding from the American Diabetes Association, Minnesota Affiliate. Dr. M. Nielsen was supported by research grants provided by the Danish Research Council, Aarhus University Hospital, and the University of Aarhus, Aarhus, Denmark.

\section{References}

1. Dinneen S, Gerich J, Rizza R (1992) Carbohydrate metabolism in non-insulin-dependent diabetes mellitus. N Engl J Med 327: 707-713

2. Radziuk J, McDonald TJ, Rubenstein D, Dupre J (1978) Initial splanchnic extraction of ingested glucose in normal man. Metabolism 27: 657-669

3. Ferrannini E, Bjorkman O, Reichard GA Jr et al. (1985) The disposal of an oral glucose load in healthy subjects. A quantitative study. Diabetes 34: 580-588

4. Firth RG, Bell PM, Marsh HM, Hansen I, Rizza RA (1986) Postprandial hyperglycaemia in patients with non-insulin-dependent diabetes mellitus. J Clin Invest 77: $1525-1532$

5. Rabinowitz D, Klassen GA, Zierler KL (1965) Effect of human growth hormone on muscle and adipose tissue metabolism in the forearm of man. J Clin Invest 44: 51-61

6. Rizza RA, Mandarino LJ, Gerich JE (1982) Effect of growth hormone on insulin action in man. Mechanisms of insulin resistance, impaired suppression of glucose production, and impaired stimulation of glucose utilization. Diabetes 31: 663-669

7. Bratusch-Marrain PR, Smith D, DeFronzo RA (1982) The effect of growth hormone on glucose metabolism and insulin secretion in man. J Clin Endocrinol Metab 55: 973-982

8. Moller N, Butler PC, Antsiferov MA, Alberti KGMM (1989) Effects of growth hormone on insulin sensitivity and forearm metabolism in normal man. Diabetologia 32: $105-110$

9. Moller N, Jorgensen JOL, Alberti KGMM, Flyvbjerg A, Schmitz O (1990) Short-term effects of growth hormone on fuel oxidation and regional substrate metabolism in normal man. J Clin Endocrinol Metab 70: 1179-1186

10. Bak JF, Moller N, Schmitz O (1991) Effects of growth hormone on fuel utilization and muscle glycogen synthase activity in normal humans. Am J Physiol 260:E736-E742

11. Jorgensen JOL, Flyvbjerg A, Lauritzen T, Alberti KGMM, Orskov H, Christiansen JS (1988) Dose-response studies with biosynthetic human growth hormone $(\mathrm{GH})$ in $\mathrm{GH}-\mathrm{de}-$ ficient patients. J Clin Endocrinol Metab 67: 36-40

12. Butler P, Kryshak E, Rizza R (1991) Mechanism of growth hormone-induced postprandial carbohydrate intolerance in humans. Am J Physiol 260:E513-E520

13. Bratusch-Marrain PR, Gasic S, Waldhausl WK, Nowotny P (1984) The effect of growth hormone on splanchnic glucose and substrate metabolism following oral glucose loading in healthy man. Diabetes 33: 19-25
14. Yalow RS, Goldsmith SJ, Berson SA (1969) Influence of physiologic fluctuations in plasma growth hormone on glucose tolerance. Diabetes 18: 402-408

15. Hartman ML, Faria ACS, Vance ML, Johnson ML, Thorner MO, Veldhuis JD (1991) Temporal structure of in vivo growth hormone secretory events in humans. Am J Physiol 260:E101-E110

16. Jaffe CA, Friberg RD, Barkan AL (1993) Suppression of growth hormone $(\mathrm{GH})$ secretion by a selective $\mathrm{GH}$-releasing hormone (GHRH) antagonist. J Clin Invest 92: 695-701

17. Levy I, Recasens A, Casamitjana R, Figuerola D (1987) Nocturnal insulin and C-peptide rhythms in normal subjects. Diabetes Care 10: 148-151

18. Shapiro ET, Polonsky KS, Copinschi G et al. (1991) Nocturnal elevation of glucose levels during fasting in non-insulin-dependent diabetes. J Clin Endocrinol Metab 72: 444-454

19. Bolli GB, De Feo P, De Cosmo S et al. (1984) Demonstration of a dawn phenomenon in normal human volunteers. Diabetes 33: 1150-1153

20. Meneilly GS, Elahi D, Minaker KL, Rowe JW (1986) The dawn phenomenon does not occur in normal elderly subjects. J Clin Endocrinol Metab 63: 292-296

21. Marshall L, Molle M, Boschen G, Steiger A, Fehm HL, Born J. (1996) Greater efficacy of episodic than continuous growth hormone-releasing hormone $(\mathrm{GHRH})$ administration in promoting slow-wave sleep (SWS). J Clin Endocrinol Metab 81: 1009-1013

22. Cappon JP, Ipp E, Brasel JA, Cooper DM (1993) Acute effects of high fat and high glucose meals on the growth hormone response to exercise. J Clin Endocrinol Metab 76: $1418-1422$

23. Moberg E, Kollind M, Lins P-E, Adamson U (1994) Acute mental stress impairs insulin sensitivity in IDDM patients. Diabetologia 37: 247-251

24. Karashima T, Cai R, Schally AV (1987) Effects of highly potent octapeptide analogs of somatostatin on growth hormone, insulin and glucagon release. Life Sci 41: 1011-1019

25. Dinneen S, Alzaid A, Miles J, Rizza R (1993) Metabolic effects of the nocturnal rise in cortisol on carbohydrate metabolism in normal humans. J Clin Invest 92: 2283-2290

26. Karhapää P, Malkki M, Laakso M (1994) Isolated low HDL cholesterol. An insulin-resistant state. Diabetes 43: 411-417

27. Butler PC, Kryshak EJ, Marsh M, Rizza RA (1990) Effect of insulin on oxidation of intracellularly and extracellularly derived glucose in patients with NIDDM. Diabetes 39: 1373-1380

28. Bell PM, Firth RG, Rizza RA (1986) Assessment of insulin action in insulin-dependent diabetes mellitus using [6$\left.{ }^{14} \mathrm{C}\right]$ glucose, $\left[3-{ }^{3} \mathrm{H}\right]$ glucose, and $\left[2-{ }^{3} \mathrm{H}\right]$ glucose. Differences in the apparent pattern of insulin resistance depending on the isotope used. J Clin Invest 78: 1479-1486

29. Steele R, Wall JS, De Bodo RC, Altszuler N, Kiang SP, Bjerknes C (1956) Measurement of size and turnover rate of body glucose pool by the isotope dilution method. Am J Physiol 187: 15-24

30. Ciaraldi TP, Molina JM, Olefsky JM. (1991) Insulin action kinetics in adipocytes from obese and non-insulin-dependent diabetes mellitus subjects: Identification of multiple cellular defects in glucose transport. J Clin Endocrinol Metab 72: 876-882

31. Brosnan JT (1982) Pathways of carbon flux in gluconeogeneis. Fed Proc 41: 91-94

32. Katz J (1985) Determination of gluconeogenesis in vivo with ${ }^{14} \mathrm{C}$ labeled substrates. Am J Physiol 17: 391-399 
33. Frayn KN (1983) Calculation of substrate oxidation rates in vivo from gaseous exchange. J Appl Physiol 55: 628-634

34. Lecoco FR, Mebane D, Madison LL (1964) The acute effect of hydrocortisone on hepatic glucose output and peripheral glucose utilization. J Clin Invest 43: 237-246

35. Rizza R, Mandarino L, Gerich J (1982) Cortisol induced insulin resistance in man: impaired suppression of glucose production and stimulation of glucose utilization due to a post-receptor defect of insulin action. J Clin Endocrinol Metab 54: 131-138

36. Nolte LA, Rincon J, Odegaard et al. (1995) Hyperglycemia activates glucose transport in rat skeletal muscle via a $\mathrm{Ca}^{2+}$ dependent mechanism. Diabetes 44: 1345-1348

37. Plat L, Byrne MM, Sturis J et al. (1996) Effects of morning cortisol evaluation on insulin secretion and glucose regulation in humans. Am J Physiol 270:E36-E42

38. MacGorman LR, Rizza RA, Gerich JE (1981) Physiological concentrations of growth hormone exert insulin-like and insulin antagonistic effects on both hepatic and extrahepatic tissues in man. J Clin Endocrinol Metab 53: $556-559$

39. Frohman LA, MacGillivray MH, Aceto T Jr (1967) Acute effects of human growth hormone on insulin secretion and glucose utilization in normal and growth hormone deficient subjects. J Clin Endocrinol Metab 27: 561-567

40. Fineberg SE, Merimee TJ (1974) Acute metabolic effects of human growth hormone. Diabetes 23: 499-504

41. Seng G, Galgoti C, Louisy P, Toussain P, Drouin P, Debry G (1989) Metabolic effects of a single administration of growth hormone on lipid and carbohydrate metabolism in normal-weight and obese subjects. Am J Clin Nutr 50: 1348-1354

42. Moller N, Jorgensen JOL, Schmitz O et al. (1990) Effects of a growth hormone pulse on total and forearm substrate fluxes in humans. Am J Physiol 258:E86-E91

43. Fowelin J, Attvall S, Von Schenck H, Smith U, Lager I (1991) Characterization of the insulin-antagonistic effect of growth hormone in man. Diabetologia 34: 500-506

44. Martha PM, Jr., Gorman KM, Blizzard RM, Rogol AD, Veldhuis JD (1992) Endogenous growth hormone secretion and clearance rates in normal boys, as determined by deconvolution analysis: Relationship to age, pubertal status, and body mass. J Clin Endocrinol Metab 74: 336-344

45. Rudman D, Kutner MH, Rogers CM, Lubin MF, Fleming GA, Bain RP (1981) Impaired growth hormone secretion in the adult population. J Clin Invest 67: 1361-1369

46. Andreotti AC, Lanzi R, Manzoni MF, Caumo A, Moreschi A, Pontiroli AE (1994) Acute pharmacologic blockade of lipolysis normalizes nocturnal growth hormone levels and pulsatility in obese subjects. Metabolism 43: 1207-1213

47. Keller U, Schnell H, Girard J, Stauffacher W (1984) Effect of physiological elevation of plasma growth hormone levels on ketone body kinetics and lipolysis in normal and acutely insulin-deficient man. Diabetologia 26: 104-108

48. Jensen MD (1995) Gender differences in regional fatty acid metabolism before and after meal ingestion. J Clin Invest 96: 2297-2303

49. Bonadonna RC, Groop LC, Zych K, Shank M, DeFronzo RA (1990) Dose-dependent effect of insulin on plasma free fatty acid turnover and oxidation in humans. Am J Physiol 259:E736-E750 